\section{De olhos abertos e fechados: estudo das narrativas de Schintzler e \\ Kubrick}

\section{RESUMO}

Nesse texto 0 autor faz uma análise das narrativas do livro Traumnovelle (de Schintzler), de 1926, e do filme Eyes wide shut (de Kubrick), de 1999, investigando como cada uma das obras constrói o estado do sonho.

\section{ABSTRACT \\ The author of this work analyses the narratives present in the book Traumnovelle (Schintzler, 1926) and in the movie Eyes wide shut (Kubrick, 1999), in order to see how each of them constructs the dream state.}

\section{PALAVRAS-CHAVE (KEY WORDS) \\ - Narrativa (Narrative) \\ - Discurso (Discourse) \\ - Estado do Sonho (Dream state)}

\section{José Luiz Aidar Prado}

Professor PEPG Comunicação e Semiótica / PUCSP
O INCONSCIENTE ESTÁ fora, diz Zizek, está nas ruas, diríamos com Kubrick, e não escondido em profundezas impenetráveis. Trata-se de afirmar a materialidade, a externalidade da ideologia, que se faz oculta sob um manto de "utilidade" (Zizek, 1997:4). As diferentes formas de se livrar das fezes nas privadas inglesa, francesa e alemã revelam o papel da ideologia, que se oculta em diferenças empíricas ligadas aos modos de se livrar dos dejetos, do excesso (idem:5). A verdade está lá no buraco da privada, diz Zizek. Se um acadêmico defende a idéia do universo pós-ideológico, após a mesa redonda irá ao banheiro e se agachará na ideologia (idem). Para Zizek, o investimento ideológico de tais referências à utilidade é atestado por seu caráter dialógico - a privada anglo-saxã adquire seu sentido somente em sua relação diferencial às privadas francesa e alemã. Temos tal variedade de tipos de privadas porque há um que cada uma tenta acomodar. O mesmo ocorre com o corte dos pêlos pubianos - "crescidos de modo selvagem, ligam-se à atividade hippie da espontaneidade natural; os yuppies preferem o procedimento disciplinar de um jardim francês; na atitude punk, a vagina é completamente raspada e adornada com anéis"(idem:6). A íntima atitude em relação ao próprio corpo é freqüentemente usada para se fazer uma proposição ideológica. "A sinceridade puramente material do ritual ideológico externo e não a profundidade de convicções e desejos internos ao sujeito é que é o verdadeiro locus da fantasia que sustenta o edifício ideológico". (idem: 6) 
É com a exibição do corpo de Alice, a esposa do médico, que Eyes wide shut começa. Ela veste-se e pergunta a Bill como está, e ele, sem olhar, responde que ela está linda. Ela reclama desta declaração sem ver e ele responde que ela sempre está linda. Ele sabe desde logo, sem precisar vê-la, que ela está linda, o que a irrita. Essa segurança de estar sempre linda para ele será questionada.

Alice colocará em questão essa constância, essa segurança do marido em relação ao desejo dela. Seria preciso que ele renovasse seu olhar em relação a ela, por um lado, e que ele soubesse que o desejo dela não está garantido para sempre, pois ele flui, escorrega sem cessar. Na festa de Vitor, após algum tempo juntos, ele vai ao banheiro e ela vira várias taças de champagne. A bebida e a maconha funcionam como actantes na queda da censura. Alice dança com um homem mais velho que o marido, que parece atraí-la e a encanta com uma conversa sedutora. Ele nota que ela observa o marido com duas mulheres e pergunta a ela:

- Não acha que o charme do casamento é tornar o fingimento necessário para ambas as partes? Por que uma mulher linda como você, que poderia ter qualquer homem dessa sala, quer estar casada? Sabe por que as mulheres se casavam? Era a única maneira de perderem a virgindade e estarem livres para fazer o que quisessem com outros homens - os que elas realmente desejassem.

- Ela responde: 'fascinante', meio inebriada pela bebida e embevecida pela dança e pela conversa sedutora do homem.

Essa frase do sedutor terá efeitos em Alice? Nada pior que a sensação de médico-marido seguro que a ama não por estar vendo-a no aqui e agora como bela e sedutora, mas por sabê-la sedutora para ele. Bill está seguro da fidelidade da esposa. A insígnia dessa plataforma de segurança do médico é o documento do conselho de medicina que ele mostra inúmeras vezes para demonstrar que ele é um profissional de confiança, um homem competente e devotado à causa dos homens. Um homem que alcançou o sucesso profissional. O sedutor húngaro traz de volta para Alice uma deliciosa sensação de ser cortejada, de ser despertada pelo olhar do outro.

A contraparte masculina dessa aventura ocorre quando Bill envolve-se numa animada conversa com duas belas modelos, deixando-se seduzir por uma conversa repleta de subentendidos e sugestões maliciosas:

-Sabe o que os médicos têm de melhor? - pergunta uma das modelos.

-Sempre parecem tão experientes.

-Onde estamos indo precisamente?

-Onde o arco-íris termina.

Elas o puxam até que esse encaminhamento é interrompido pelo funcionário de Vitor, o anfitrião, que o chama com urgência.

Num aposento, uma mulher nua, Mandy, está desmaiada no sofá. Vitor explica que foi acidente, tendo ela misturado cocaína e heroína. O médico a acorda e explica o perigo da situação. A cena é entrecortada com a dança entre Alice e o húngaro - ele a convida para ir à galeria no pavimento superior. Mandy recupera os sentidos. Vitor pede a Bill que o caso fique em segredo.

O médico ajuda o milionário casado a livrar-se do problema da quase-morte da mulher devido ao consumo de drogas. O médico tem de servir ao cliente rico e guardar segredo profissional. Mais tarde, ele verá como se divertem os ricos; tentará, quase à custa da própria vida, conhecer o gozo desses clientes ricos. De volta à cena da dança, Alice recupera subitamente a atenção, e diz que bebeu demais e precisa procurar o marido. 
A seguir Alice está diante do espelho, nua. Bill a beija, mas ela olha de lado, como se outra coisa desviasse sua atenção, como se, além do marido, outro objeto pudesse preencher sua fantasia naquele momento. O não-olhar do marido, a fala e o olhar sedutores do húngaro parecem ter aberto um outro ponto de vista para Alice. É a cena emblemática do filme, em que a mulher parece ter outro objeto a atraí-la enquanto se entrega às carícias do marido. Tal não é a mesma problemática do livro.

A cena seguinte ocorre no dia-a-dia do consultório, com uma mulher despida sendo atendida por ele, com ajuda da assistente. Essa cena é entrecortada pela da filha de Bill, em sua casa, retornando a outros atendimentos no consultório. De um lado, o médico aparece em seu cotidiano profissional, de outro Alice está posta na família como mãe.

No livro fica muito claro o jogo simétrico de ocultamento e descoberta que o médico e a mulher estabeleciam nesse terreno em que atuava "o incompreensível vento do destino", que poderia, ao sabor da aventura, "ainda que apenas em sonho". Mesmo os encontros do baile não anunciavam relações concretas de um e outro com outros parceiros sexuais, mas somente aventuras sem conseqüências dentro de uma atmosfera fantasmática, que depois seriam confessadas ao outro. Kubrick desloca essa simetria de escondeesconde, construindo uma assimetria, enfatizando a própria idéia do livro de que Albertine-Alice começa a contar primeiro sua fantasia por ser mais honesta. No filme a conversa é mais referencial e Alice pergunta diretamente se ele trepou com as modelos. Ela o faz após o casal fumar maconha:

- Estou falando das duas garotas que você estava paquerando tão descaradamente.

- Eu não estava paquerando ninguém.

- Quem eram?

- Só umas modelos.
- E por que sumiu com elas tanto tempo?

- Eu não sumi com ninguém. Ziegler não estava se sentindo bem e fui chamado. E quem era aquele cara dançando com você? O que ele queria?

- Sexo. No andar de cima. Ali mesmo, na hora. - A resposta dela é honesta e direta, sem subterfúgios, ao contrário do médico, que jamais dá resposta direta.

- Só isso? Só queria comer a minha mulher? Acho isso compreensível.

Ela se irrita com o "compreensível". Nesse terreno que o livro chama de "incompreensível vento do destino", nada é compreensível, coisa que o médico não assume. Ele explica por que pensa isso ser "compreensível":

- Por que você é uma mulher muito bonita.

Ela se levanta contrariada.

- Ser uma mulher bonita é a única razão pela qual os homens querem falar comigo. Eles querem me comer. É isso que você está dizendo?

- Imagino que sabemos como os homens são.

- Então, com base nisso, devo concluir que você queria trepar com aquelas modelos.

- Há exceções.

- O que faz de você uma exceção?

- O que me torna uma exceção é que te amo, somos casados e nunca mentiria para você ou te feriria.

- Você está se dando conta de que está dizendo que só não comeu aquelas modelos porque tem consideração por mim e não porque realmente não queria?

- Essa erva está deixando você...

- Por que nunca me dá uma resposta direta?

De fato, Bill não responde diretamente 
às questões de Alice, não assume que as moças queriam trepar com ele, não explica se escolheu não trepar com elas ou se simplesmente foi interrompido por Ziegler. Alice prossegue:

- Digamos que uma mulher deslumbrante esteja nua em seu consultório. O que você pensa ao apertar os peitos dela?

- Alice, acontece que sou um médico. Há sempre uma enfermeira junto. É só profissionalismo. Sexo é a última coisa em que penso quando estou com uma paciente.

- Enquanto médico, ele diz não pensar em sexo, estando apenas interessado em atender as pessoas. O médico se coloca como técnico, não sendo dirigido pelo incompreensível vento do destino.

- (...)

- Os homens só pensam em trepar

e as mulheres só em segurança e compromisso? - pergunta Alice.

- É mais ou menos isso.

- Ah, se vocês homens soubessem... Por que você nunca teve ciúmes de mim?

- Porque você é minha esposa, mãe de minha filha e nunca seria infiel a mim.

- Como você é autoconfiante!

- Eu confio em você.

Ela desata a rir, convulsivamente.

-"Você se lembra do verão passado em Cape Cod? No restaurante havia um jovem oficial da marinha sentado perto de nossa mesa com dois outros oficiais. O garçon entregou um recado e ele saiu. Eu já o tinha visto naquela manhã. Olhou para mim de relance ao passar. Foi só um olhar. Mas eu mal consegui me mexer. Naquela tarde Helena foi ao cinema com uma amiga e eu fiz amor com você. Nós fizemos planos sobre o futuro e falamos sobre Helena. Em nenhum momento deixei de pensar nele. Se ele me quisesse mesmo que fosse só por uma noite eu estava pronta para abandonar tudo, você, Helena, todo o meu futuro. Tudo. No entanto, foi estranho, você foi mais precioso para mim do que nunca. Naquele momento, meu amor por você era suave. Nem dormi naquela noite e acordei em pânico na manhã seguinte. Eu não sabia se tinha medo de que ele tinha partido ou se ainda estivesse lá. Mas no jantar percebi que ele havia ido embora e fiquei aliviada".

No livro essa cena é construída de modo diverso, pois tanto Albertine conta a fantasia com o marinheiro, como Fridolin conta-Ihe que antes dela acordar ele caminhava pela praia. Nunca encontrava ninguém, até que numa manhã:

"avistei de repente uma figura de mulher; ainda invisível havia um instante, ela agora se movia cuidadosamente pelo estreito terraço de uma cabine com suas estacas fincadas na areia, colocando um pé na frente do outro, os braços estendidos para trás, apoiados na parede de madeira. Era bastante jovem, uma menina de uns quinze anos, talvez, tinha os cabelos loiros soltos sobre os ombros, escorrendo de um dos lados sobre o seio macio. Olhava para a frente, para a água mais embaixo, e, devagar, deslizava ao longo da parede, rumo à outra extremidade, os olhos baixos, até que, de repente, estava bem diante de mim; com os braços, buscou apoio atrás de si, como se quisesse agarrar-se com maior firmeza, ergueu os olhos e então, de súbito, avistou-me. Um tremor percorreu-lhe o corpo, como se não lhe restasse outra alternativa senão afundar ou fugir. Mas como, sobre a estreita tábua, só pudesse mover-se adiante com bastante 
vagar, decidiu deter-se - e lá estava ela agora, a princípio assustada; depois, furiosa, e, por fim, com uma expressão de constrangimento no rosto. Mas, de repente, sorriu um sorriso maravilhoso; em seus olhos havia um cumprimento, um aceno - e, ao mesmo tempo, uma velada zombaria, munida da qual roçou de leve a água a seus pés, a água que a separava de mim. Então, endireitou o corpo jovem e esbelto, como que contente com a própria beleza e, como se podia notar com facilidade, orgulhosa e docemente exaltada ao sentir sobre si o brilho do meu olhar. $\mathrm{E}$ ali permanecemos um diante do outro por uns dez segundos, talvez, com os lábios entreabertos e os olhos cintilantes. Invo-luntariamente, estendi os braços em sua direção, seu olhar revelando abandono e alegria. De súbito, porém, ela balançou a cabeça com veemência, afastou um braço da parede e indicou-me de modo categórico que eu deveria me afastar" (Schnitzler,2000:13-14).

Essa diferença é fundamental para nossa compreensão do cerne da adaptação de Kubrick. No livro os personagens, bem mais simétricos do que no filme, parecem figuras idealizadas inseridas dentro de uma narrativa que ilustra esse movimento inconsciente que leva as pessoas metonimicamente no rumo do desejo do outro, seguindo uma força-desejo cuja lógica é oculta. Num certo sentido, a posição do médico, enquanto um técnico do corpo, ditando aos demais modos saudáveis de comportamento, se contrapõe diretamente à lógica de deslizamento, realizada pelo trabalho do sonho.

Com o relato de Alice, acabarão a certeza e a autoconfiança de Bill, ditadas pelo status e pela ética médica, que orienta as condutas dos demais, e ele passará a ser invadido pela fantasia do marinheiro que trepa com Alice, nas cenas em PB, que retornarão inúmeras vezes, como um sonho mau. Nada ocorreu na prática, pois Alice na realidade não trepou com o marinheiro, mas a cena virtual foi construída pelo discurso de Alice ao afirmar que desejou o marinheiro. Rompida essa plataforma narcísica do pódio que sustentava o eu-ideal do médico, ele estará sujeito ao movimento pulsional que o levará de bar em bar. O marinheiro, actante da fantasia de Alice, salta de um script a outro e passará a atuar na fantasia mortal de Bill, ameaçando-o sem cessar.

No livro, após a confissão mútua, que era de certo modo freqüente entre eles, realizando uma forma de tentativa de equilibrar o lado pulsional do "destino", de lidar com o lado traumático do sexo, Fridolin afirma: "Em cada criatura que julguei amar, estava apenas e sempre procurando por você. Sei disso melhor do que você é capaz de compreender". Albertine responde: "E se também eu tivesse partido nessa busca (...) Ah, se vocês soubessem..." E conta-Ihe que na noite anterior ao pedido de casamento ela teria se entregado a ele se ele tivesse dito a palavra certa, mas ele não o fez. De certo modo, ela sempre esperou a palavra certa de um homem, a atitude certa, a verdade liberada de um comportamento socialmente adequado. O marinheiro representa justamente esse sem rumo do destino, do desejo de Alice-Albertine e se opõe à segurança e ao controle da figura do médico, contido, sempre com a palavra adequada de médico na boca, mas sem a palavra certa na hora do amor e da paixão.

De certo modo, o médico-sempremédico (expressão do próprio Bill ao falar com o pianista) é essa figura de classe média renovadamente imersa em atitude profissional, em roupas severas, escuras durante a noite e brancas durante o dia, sempre adequadas às normas sociais ou do interesse, que orienta os outros quanto aos procedimentos de saúde, e por que não dizer, morais, mas sob um código de silêncio, como no caso de Vitor e Mandy. Ele jamais oferece a palavra "certa", 
desejada pela mulher, palavra orientada não por razões de uma lógica sistêmica, contabilizadora, para lembrar o Lacan de Encore. O gozo Outro é o que caracteriza em Lacan o feminino, diferenciando-o do masculino. Bill jamais é totalmente sincero, como Alice, e nunca está disposto a romper com as normas do ajuste social, exceto após ver essa posição de segurança (do eu ideal) rompida pela fantasia da mulher (no filme) ou dos dois relatos (do marinheiro e da noite anterior ao noivado), no livro.

A seguir toca o telefone e Bill é chamado pela filha de um paciente, Lou Nathanson, que morrera. Aí começa a peregrinação que envolverá várias figuras ligadas ao sexo e à morte. De táxi em táxi, ele andará pelas ruas, sem destino, levado pelo vento do destino e da pulsão, perseguido pela cena do marinheiro na cama com Alice.

$\mathrm{Na}$ rua, após a visita ao morto Nathanson, Bill segue a pé. Novamente ele é invadido pela cena fantasmática do marinheiro. Um grupo de jovens passa, chamando-o de "bicha". Ele está na posição frágil de incompetente, de perdido nas ruas, de traído, sem ter de fato sido traído, confundindo traição com abertura do desejo da mulher. No livro ele sente o joelho tremer e pergunta-se se estava sendo covarde:

"Eu vou agora atracar-me com um estudante bêbado - eu, um homem de trinta e cinco anos, médico formado, casado e pai de uma filha? Desafio! Padrinhos! Duelo! E, no fim, levar uma estocada no braço por causa de um esbarrão tão tolo? Não poder trabalhar por uma, duas semanas? Ou perder um olho? Ou mesmo ter uma infecção generalizada? E, em oito dias, estar como o paciente da rua Schreyvogel, sob a coberta de flanela marrom! Covardia? Tinha enfrentado três duelos com o sabre, certa vez, estivera pronto a enfrentar até mesmo um duelo de pistola, um episódio cuja resolução amigável não se devera, aliás, à iniciativa dele. E sua profissão! Exposto a perigos de todos os lados e a todo momento - só que as pessoas sempre se esqueciam disso. Quanto tempo fazia que aquela criança diftérica havia tossido bem no seu rosto?"(Schnitzler, idem: 31)

Ele se lembrará, no final do livro, novamente dessa criança mortal. Após a conversa com a esposa, as figuras da morte passaram a invadi-lo. O medo passa a insinuar-se em sua vida. Performativamente ele vai caminhando pelas ruas, como um anti-sujeito levado pelo inconsciente, sem destino, como se suas ações o levassem para esse não-lugar, para o descaminho do sonho e da fantasia mortal. O trabalho de sonho é no filme justamente esse deslizamento do médico nas ruas, de táxi em táxi, de porta em porta, em busca de um rumo ignorado, passando por uma série de riscos. Seu mundo é agora o das ruas repletas de sexo e morte, de promessas e perigos, o das prostitutas, das crianças diftéricas transmitindo-lhe a morte, dos estudantes insultando-o sem que ele reaja e do marinheiro comendo sua mulher, que goza com isso. A prostituta com quem ele sai - e ele só saberá disso no dia seguinte - está com HIV positivo. Ele está deslocado do próprio Lebenswelt, está perdido em jouissance mortal, dirigido, ao mesmo tempo, pela pulsão sexual.

$\mathrm{O}$ que a mulher the pede, e é essa a razão dela ter falado da fantasia do marinheiro, é que ele possa sair dessa posição de homem-médico bem-sucedidofálico, e diga a palavra certa, de homem castrado e aberto para um Outro gozo, não contabilizável pela lógica disciplinadora do mundo do consultório. Talvez no mundo pós-moderno a mulher realmente trepasse com outro e the contasse para dividi-lo, para quebrar sua compulsão-medicalista. De qualquer modo, ele não tem ouvidos para essa intervenção e ouve o relato da mulher como a narrativa de uma traição, 
que o ameaça e o destitui.

Encontra outras figuras de mulher, como a solteira infeliz que cuida do pai doente, a pierrete adolescente, filha do dono da loja de fantasias, prostituída pelo próprio pai, e a mulher mascarada do baile bacanal.

Ele quer vingar-se de sua esposa, já não pode ouvi-la. Mas de outro lado, de modo ambivalente, ele não consegue traí-la, não trepa com a prostituta, não se envolve com outras mulheres, apenas circula sem norte. Como renovar sua relação com a mulher fora do registro de um amor assegurado e assujeitado à esfera do ser-médico, do ajuste social contabilizador e normatizador, registro da segurança do profissional bem-sucedido? Parece ser esse o limite do masculino: trepar é foder para contabilizar as fodas, permanecer no poder e jamais lidar com o desejo de modo aberto e franco. Pede-lhe demais a mulher? Ela mostra o amante como signo de ameaça.

Bill entra depois no café em que trabalha o pianista Nick Nightendale, seu antigo colega da faculdade de medicina, que desistira do curso, e tornara-se pianista viajante, e fica sabendo que o pianista tocará num lugar, de olhos vendados, ou de olhos bem fechados, em que se exige senha para entrar. Nick fica sabendo do local exato uma hora antes do evento. Bill insiste em ir. Nick explica que é necessária uma fantasia e uma máscara. No livro a senha é Dinamarca, que também se refere à viagem em que ela conheceu 0 marinheiro fálico. No filme é Fidelio.

No baile bacanal tanto o médico como o pianista estarão, cada um a sua maneira, de olhos bem fechados. O médico fica de olhos fechados ao perder sua segurança de alguém bem localizado profissional e socialmente, que sabe onde circular e como se comportar diante de seus clientes ricos e diante dos mais pobres, que vendem a ele seus serviços e ele sempre dá gorjetas. Ao fechar dos olhos, reina a fantasia e a ideologia, que o tira da posição de sujeito, que o tira da posição reforçada pelo ideal de eu.

Após retornar da festa bacanal, a esposa Ihe conta um sonho em que trepava com muitos homens em um salão. No livro o sonho é diferente - na noite do noivado, ela abre o guarda-roupa e em vez do vestido de casamento encontra fantasias. Ele chega em uma galera com escravos remando, e ela se vê também em trajes de princesa. Tomou-a nos braços e amoua muito. No dia seguinte, acordaram e as roupas tinham sumido. Ela sentiu-se envergonhada e apavorada e sentiu que ele era o culpado. Ele foi buscar roupas. Ela sentiu-se aliviada e passou a correr pelos campos. O dinamarquês surgiu, e desapareceu, repetidamente. O noivo corria pela cidade procurando roupas. E ela finalmente deitou-se na grama com o dinamarquês. $O$ noivo fora preso e iria ser executado. Ela sentiu uma sensação de grande liberdade, como nunca na vida real. A princesa propõe-se a salvá-lo desde que ele fosse seu amante, mas ele se recusa e ela diz que era natural que ele fosse fiel a ela por toda a eternidade. E ele morre pregado na cruz. Albertine assume uma posição de crueldade no sonho.

Voltemos ao filme. No dia seguinte ele vai ao consultório, mas não consegue trabalhar. Precisa prosseguir na rota de sonho da noite anterior. Vai devolver a fantasia, procurar o pianista, etc. Fica sabendo da morte de sua salvadora na festa pelo jornal - era uma ex-miss beleza. Vai ao necrotério ver seu corpo. Ficará sabendo depois, por Vitor, que era Mandy, a prostituta que o médico tinha atendido em sua casa. No livro a morta é a baronesa $D$.

A peregrinação termina com a confissão de Bill-Fridolin à esposa de tudo o que se passara. Ele pergunta a ela: "O que vamos fazer?" Ela diz:

- Agradecer ao destino por termos escapado incólumes de todas as aventuras - as reais e as sonhadas. (...) Estou tão certa quanto suspeito que a realidade de uma noite ou 
mesmo a realidade de toda uma vida não significa sua verdade mais íntima.

Ele responde:

- Agora estamos os dois acordados e por muito tempo.

Esse final revela algo como um efeito pedagógico psicanalítico, ao colocar um aprendizado do inconsciente, a verdade sob a barra, presente no que os lacanianos chamam de travessia da fantasia, como resultado geral das peregrinações e desencontros dos dois. No filme ocorre algo a mais. Depois disso tudo, dessa lição de moral explicitada na sanção final, Alice diz:

- Só resta uma coisa..... trepar.

\section{A fantasia}

Voltemos a Zizek - a fantasia é costumeiramente pensada como sendo um cenário que ofusca o horror verdadeiro de uma situação - "Ao invés de uma completa submissão a antagonismos que atravessam nossa sociedade, nós nos entregamos a uma noção de sociedade como um todo orgânico, mantido coeso por forças de solidariedade e cooperação." (Zizek,idem:6) Zizek considera que essa não é a melhor via. Devemos examinar a noção de fantasia por outro viés, onde ninguém espera encontrá-la, nas situações marginais e puramente utilitárias. A noção psicanalítica de fantasia vai além desse cenário ofuscante:

"A relação entre a fantasia e o horror do real que ela esconde é muito mais ambígua do que parece - a fantasia esconde esse horror, mas ao mesmo tempo cria o que ela procura esconder, seu reprimido ponto de referência" (idem:7).

Assim, a fantasia não realiza um desejo num modo alucinatório, pois sua função é similar:

"ao esquematismo transcendental kantiano - uma fantasia constitui nosso desejo, dá suas coordenadas; ou seja, ela literalmente 'ensina-nos como desejar'. (...) A fantasia faz a mediação entre a estrutura simbólica formal e a positividade dos objetos que encontramos na realidade, fornece um 'esquema' de acordo com o qual certos objetos positivos podem funcionar como objetos do desejo, enchendo os lugares vazios abertos pela estrutura simbólica formal. (...) A fantasia não significa que, quando desejo um bolo de morango e não posso tê-lo, fantasio em comêlo; o problema é antes - como sei que desejo um bolo de morango em primeiro lugar?; Isto é o que a fantasia me diz."(idem:7)

Esse papel da fantasia liga-se à famosa galhofa de Lacan com a frase "a relação sexual não existe", o que não significa evidentemente que as pessoas não trepam, mas que não há proporção entre os sexos, ou seja, que não há matriz universal que garanta uma relação harmônica com o parceiro. Devido a essa falta, todo sujeito tem de inventar uma fantasia própria, uma fórmula particular para a relação sexual. "Cada homem ou mulher tem um ponto a regular o desejo. Esse conhecimento não pode ser subjetivado - é estranho (uncanny), mesmo horrorífico. Ele de certo modo despossui o sujeito, reduzindo-o a um nível de fantoche, além da dignidade e liberdade" (idem:8).

Eyes wide shut mostra a destituição do ponto imaginário de sustentação do médico que se vê diante da morte (o horror da criança diftérica, a agressão dos estudantes, a Aids e a ameaça de morte na festa). Em seu nível mais fundamental, escreve Zizek, a fantasia diz de mim o que sou para os outros, o que o Outro vê em mim. De algum modo, a fantasia de Alice 
em relação ao marinheiro fora ativada pelo olhar do estranho, como se ele tivesse naquele momento transmitido a ela o mais secreto dela a ela mesma, um tesouro que é sempre dito estar nas mulheres. $\mathrm{E}$ ela estava disposta a largar tudo SE ele a tivesse chamado. Da mesma forma, no livro Albertine afirma que teria trepado com o médico-noivo mesmo antes do casamento se ele tivesse dito a palavra certa. Esse chamado virtual vinha do Outro, não de uma pessoa de carne e osso.

No livro, Albertine afirma: "Não dependeu de mim tornar-me sua esposa ainda virgem"(Schnitzler,idem:16). Se ele tivesse dito uma única palavra, a palavra certa, ela teria saído com ele pela pradaria, passearia por onde ele quisesse, até a floresta, na canoa e ele poderia ter tido tudo o que quisesse. "Mas ele não disse a palavra, aquele jovem encantador; apenas beijou com ternura a minha mão e, na manhã seguinte, perguntou-me se aceitaria ser sua esposa" (idem).

A esposa põe em questão a posição de marido seguro, autoconfiante, que se liga de alguma forma à posição euforizada de médico que atende os ricos, a quem a mulher deve entregar-se toda, de olhos bem fechados. Essa posição do Bill antesdas-ruas é ditada pelo modo pelo qual o médico é visto pelos clientes ricos. A mulher se entrega a ele, mas de olhos semifechados, dirigidos a um ponto lateral em relação à câmera. A forma pela qual ele se vê todo-fálico é confrontada pela fantasia narrada pela mulher.

A partir daí, ele se assumirá o papel de marido traído. Ao invés de entender que não deve se colocar como médico todo-fálico vestido pela compulsão, ele se coloca como o corno do senso comum. Essa fantasia o levará a uma peregrinação noturna (na forma do sonho) em busca de um olhar que lhe devolva a posição de segurança posta em questão. Jamais a terá. A forma dessa peregrinação é a do sonho. Os indícios são as situações às quais ele se expõe, de vulnerabilidade, de encontrar-se num lugar proibido, de ter de revelar sua identidade e despir-se diante de todos os mascarados, de erotização das situações (a filha do morto afirma amá-lo, a prostituta não cobra dele, a filha do dono da loja se oferece a ele, a prostituta Mandy dá a vida para salvá-lo, o significante arcoíris reaparece no sonho, etc.). A festa do sonho é algo como o inverso da festa na casa de Vitor, criando uma relação latente/ manifesta. Entretanto, a festa do sonho, a festa dos mascarados não é apresentada como sonho de um homem, mas como um sonhar acordado em um espaço da realidade vivido como um sonho desejado pelo médico, espécie de fantasia burguesa em relação à liberdade/libertinagem da elite. As mulheres se lançam para ele, mas ele sempre vai embora. De certo modo, nenhuma restitui a ele o olhar que ele buscava. De que ponto de vista ele quer ser visto? Na festa bacanal ele encontra outro mundo, regido por outras regras, mortais, em que o casamento não dita as condutas. Sem a demonstração do rosto, tudo se permite na orgia pública repleta de novos rituais. Mas ele está no lugar errado, sua posição social não é essa.

A fantasia não está somente nas mentes dele e da mulher, mas nas estruturas do mundo, na medida em que, liberado o mecanismo da censura e da repressão, aparecem os antagonismos - o desejo leva sempre metonimicamente o médico para outro lugar, sempre passando pelas ruas repletas de perigos, onde novos perigos surgem, com novas mortes, desde a do pai de Marion, até o estudante que o ofende e ele é levado a pensar no duelo. Ou mesmo o baile bacanal, em que não domina a censura sexual e em que qualquer desvio da norma da seita é punido com a morte. Nesse sonho acordado em que ele se lança de olhos bem fechados, provocado pelos olhos abertos do desejo da mulher, uma outra mulher, Mandy, terá de dar a vida para salvá-lo. Alguém morre por ele, para que ele recomece castrado. De certo modo, ele tem de reestruturar 
seu ideal-de-eu como médico que inspira confiança ao apresentar a identificação do conselho de medicina, pois ele causou a morte de alguém. O médico Bill salvara Mandy, mas o homem Bill precisará dessa morte para continuar sua vida. Aí opera uma divisão do tipo médico-monstro, ordem-desordem nos ideais de um integrante da classe média alta.

No livro não são narradas as relações sexuais que ocorrem no filme. Ele sai da festa bacanal sem nem mesmo saber de que se tratava o local. Andando na neve, ele:

"Jurou não descansar enquanto não encontrasse a bela mulher cuja ofuscante nudez o embriagara. $E$ somente nesse momento pensou em Albertine - mas o fez como se, em primeiro lugar, tivesse de conquistar também ela, como se ela não pudesse, não devesse ser de novo sua antes que ele a houvesse traído com todas as outras daquela noite - com a mulher nua, com a pierrete, com Marianne, com a prostituta da ruazinha estreita. E não deveria esforçar-se por encontrar o estudante insolente que o empurrara, a fim de desafiá-lo para um duelo de sabres, ou melhor ainda, de pistolas? O que Ihe importava a vida de outra pessoa, o que lhe importava a sua própria? Tinha-se sempre de pôr a vida em jogo apenas por dever, por uma disposição para o sacrifício, e nunca por capricho, paixão ou apenas para medir-se com o destino?"

\section{A hipótese repressiva}

Disso tudo poderíamos pensar que a elite detentora do poder e do dinheiro goza, no espaço não-manifesto, o gozo do Maître, em que os rostos não podem se revelar. As normas de sexualidade da classe média, por outro lado, são diversas, como é o caso do médico e de sua esposa. No filme, Alice é quem dá o fecho do filme: após confundirmos sonhos e fantasias, após nos perdermos em sonhos acordados, deve-se agradecer ter escapado incólumes de todas as aventuras - e a única saída é trepar. A melhor saída do psicanalizado é virar as costas ao divã e à sociedade de psicanalistas e não se tornar um psicanalista.

Foucault, que nega a hipótese repressiva (pois jamais falou-se tanto de sexo), parece dizer algo semelhante. Nesse sentido, como sintetiza Chauí, "a idéia central de Foucault é que a liberação sexual, se for possível, não passa pela crítica da repressão sexual, mas pelo abandono do discurso da sexualidade e do objeto sexo e pela descoberta de uma nova relação com o corpo e com o prazer."(Chauí, 182) O que diz Alice é: após atravessar as fantasias, pode-se finalmente trepar. Chega de tantos discursos sobre a sexualidade, de tanta ciência do corpo. Só resta trepar. Com o marido e, eventualmente, com o marinheiro...

A ciência sexual, nascida no fim do século 18 e desenvolvida durante os séculos 19 e 20, é um conjunto de disciplinas científicas e de técnicas relativas ao comportamento sexual: pedagogia, medicina, direito, economia, demografia, psiquiatria e psicanálise seriam suas principais componentes (Foucault, 1984).

Nos séculos seguintes houve uma explosão discursiva, provocando um movimento centrífugo em relação à monogamia heterossexual. A moralização do sexo pela família e pelo trabalho infla a psicanálise. Guattari criticará mais tarde esse exagero de colocar a família em primeiro plano.

As mudanças que ocorrem no século 18 com a família levaram a uma privatização e aburguesamento, condenando as depravações da nobreza, valorizando o pudor, a decência, a limpeza e o isolamento ou privacidade (Chauí, idem:129). Para Foucault o sexo assume 
um foco cada vez mais intenso na disputa política. Faz parte das disciplinas do corpo: "Adestramento, intensificação e distribuição das forças, ajustamento e economia das energias" (Chauí, idem:136).

Ao escolher um sujeito-médico para a narrativa, Schnitzler se mantém no centro desse movimento centrípeto que coloca em questão a identidade do sujeito. Trata-se de alguém que representa essa classe de senhores burgueses que desde o começo do século 19 ditava as normas médicas sobre a sexualidade e a vida saudável. No filme, apesar da insígnia do médico não atuar do mesmo modo que no livro, ainda tem força, enfatizando um certo ideal de assepsia, de quem mexe nos corpos, cuidando deles sem erotizá-los. A questão é que a mulher do médico quer gozar, quer trepar com um homem que goze com ela. É esse o dito que arrebenta o médico: eu vi no marinheiro o olhar de homem que me fará gozar, enquanto você me quer como a adestrada mulher de médico.

Para Foucault o sexo é um ponto imaginário, instalado pelo dispositivo da sexualidade. Essa idéia de sexo, diz Foucault, permite esquivar o que constitui o "poder" no poder, permite pensá-lo como lei e interdição:

"O sexo, essa instância que parece dominar-nos, esse segredo que nos parece subjacente a tudo o que somos e liberar-nos o que nos define, o sexo nada mais é do que um ponto ideal tornado necessário pelo dispositivo de sexualidade e por seu funcionamento. Não se deve imaginar uma instância autônoma do sexo que produza, secundariamente, os efeitos múltiplos da sexualidade ao longo de toda a sua superfície de contato com o poder. $\mathrm{O}$ sexo é, ao contrário, o elemento mais especulativo, mais ideal, e igualmente mais interior, num dispositivo de sexualidade que o poder organiza em suas captações de corpos, de sua materialidade, de suas forças, suas energias, suas sensações, seus prazeres" (Foucault, 1984:145).

Diríamos que Fridolin-Bill perdeu seu ponto de apoio, sua identidade imaginária apoiada na posição de médico e de marido amado pela esposa, cujo desejo deveria ser a ele exclusivamente dedicado, e embarcou numa aventura pelas ruas repletas de uma sexualidade não normalizada, desviada. Isso simboliza o que os psicanalistas lacanianos chamam de travessia da fantasia, espécie de trajeto rumo a um conhecimento mínimo do analisante em relação a suas formas de gozo. Num certo sentido, o médico tem de atravessar a fantasia para retornar ao lar. É só ao aceitar a castração que ele pode retornar ao casamento. Se por um lado esse final do filme de Kubrick aponta, após a travessia da fantasia, para um "chega de falar e de imaginar e vamos trepar", por outro, nada diz das mudanças de Bill enquanto médico. $\mathrm{O}$ que essa travessia teria alterado em seu ser-médico?

Como entender nesse processo a ação de Freud e da psicanálise? A psicanálise, afirma Foucault, nada inventou no sentido de que se tratava de um processo que começara havia muito tempo. Aqueles que formularam a tese do pansexualismo

"tinham atribuído ao gênio mau de Freud o que estava preparado havia muito tempo; tinham-se enganado de data quanto à instauração, em nossa sociedade, de um dispositivo geral da sexualidade. Mas os outros (os que rejeitaram essa tese) erraram quanto à natureza do processo; acreditaram que Freud restituía, enfim, ao sexo, por uma reversão súbita, a parte que lhe era devida e que lhe fora contestada por tanto tempo; não viram que o gênio bom de Freud o colocara em um dos pontos decisivos, marcados, desde o século 18, pelas estratégias de saber e poder; e 
que, com isso, ele relançava com admirável eficácia, digna dos maiores diretores espirituais da época clássica, a injunção secular de conhecer o sexo e colocá-lo em discurso."(Foucault, idem:149)

É por essa razão que a leitura do filme deve restituir o aspecto de materialidade do social e da cultura na confecção dos discursos e das práticas sexuais .

Nota

José Luiz Aidar Prado é professor do Programa de Estudos Pós-graduados em Comunicação e Semiótica da PUCSP. É bacharel em filosofia pela USP e autor de Brecha na comunicação. É co-autor de Lugar Global Lugar Nenhum.e organizador de Crítica das Práticas Midiáticas.

\section{Referências}

CHAUÍ, M. (1985) Repressão sexual. Essa nossa (des)conhecida. 8 a ed. São Paulo, Brasiliense.

FOUCAULT, M. (1984) História da sexualidade. 5a. ed. Rio de Janeiro, Graal.

LACAN, J. (1985) Mais, ainda. $2^{\text {a }}$ ed. Rio de Janeiro, Zahar.

SCHNITZLER, A. (2000) Breve romance de sonho. São Paulo, Cia das Letras.

ZIZEK, S. (1997) The plague of phantasies. London, Verso. 